\title{
STUDY OF MAOWUSU SANDY LAND VEGETATION COVERAGE CHANGE BASED ON MODIS NDVI
}

\author{
Qin YE ${ }^{1}$, Hang LIU ${ }^{1}$, Yi LIN ${ }^{1}$, Ruimei HAN ${ }^{2, *}$ \\ ${ }^{1}$ College of Surveying and Geo-informatics, Tongji University, Shanghai 200092, China, (yeqin, liuhang, linyi)@tongji.edu.cn \\ ${ }^{2}$ College of Surveying and Land Information Engineering, Henan Polytechnic University, Jiaozuo 454000, China, hrm@ hpu.edu.cn
}

\author{
Commission III, WG III/10
}

KEY WORDS: Normalized Differential Vegetation Index, Vegetation Coverage, Maowusu Sandy Land, Maximum Value Composite, Pearson Correlation Coefficient, Inverse Distance Weighting

\begin{abstract}
:
This paper selected 2006-2016 MODIS NDVI data with a spatial resolution of 500m and time resolution of 16d, got the 11 years' time series NDVI data of Maowusu sandy land through mosaicking, projection transformation, cutting process in batch. Analysed the spatial and temporal distribution and variation characteristics of vegetation cover in year, season and month time scales by maximum value composite, and unary linear regression analysis. Then, we combined the meteorological data of 33 sites around the sandy area, analysed the response characteristics of vegetation cover change to temperature and precipitation through Pearson correlation coefficient. Studies have shown that: (1) The NDVI value has a stable increase trend, which rate is $0.0075 / \mathrm{a}$. (2) The vegetation growth have significantly difference in four seasons, the NDVI value of summer > autumn > spring > winter. (3) The NDVI value change trend is conformed to the gauss normal distribution in a year, and it comes to be largest in August, its green season is in April, and yellow season is in the middle of November, the growth period is about $220 \mathrm{~d}$. (4) The vegetation has a decreasing trend from the southeast to the northwest, most part is slightly improved, and Etuokeqianqi improved significantly. (5) The correlation indexes of annual NDVI with temperature and precipitation are -0.2178 and 0.6309 , the vegetation growth is mainly affected by precipitation. In this study, a complete vegetation cover analysis and evaluation model for sandy land is established. It has important guiding significance for the sand ecological environment protection.
\end{abstract}

\section{INTRODUCTION}

Vegetation is an important part of the ground ecological system and plays the role of "indicator", vegetation coverage can reflect the security and stability of the ecological environment (Lamchinet et al., 2016). The ecological environment and its variation are extremely important for the ecological environment governance in the desert area, since the ecological environment in the desert area is fragile (Wang et al., 2017; Songet al., 2011; $\mathrm{Li}$ et al., 2012). There are two vegetation coverage determination methods: measuring in field and determining based on remote sensing image. Although the former can get more accurate data, it is inefficient. At present, the remote sensing technology is mainly used to obtain the vegetation coverage in large area (Setiawan et al., 2014; Lin et al., 2016; Jiapaer et al., 2011). The inversion of vegetation coverage information based on remote sensing image has the advantages of long time serial, wide range, data access convenience, high spatial resolution, so it can well describe and analyze the spatial-temporal characteristics of vegetation and be widely used in related fields (Xiao et al., 2017; Mu et al., 2012; Du, J., Zhao et al., 2015). Zhu et al. (2017) used the GIMMS-NDVI data to analyze the changes of vegetation cover in Hunshandake Sandy Land from the annual and monthly time scales. However, the GIMMS-NDVI data set covers only 1981-2006 with a low spatial resolution of $8 \mathrm{~km}$. It can't express the spatial variation of vegetation cover in recent years clearly. MODIS-NDVI as a continuation of GIMMS-NDVI products, and has a higher spatial resolution, can better describe the temporal and spatial variation of vegetation. Wang et al., (2016) using the MODIS-NDVI data and meteorological data of the growing season from 2000 to 2013 to study the dynamic change of desertification and its response to regional climate change in Keer Sandy Land, due to only the growing season's data is selected, they can't analyze the law of vegetation growth during the year.

Desertification is a serious threat to the ecological environment. With the promulgation and implementation of ecological restoration policies, the desertification has been improved (Zhao et al., 2003), but the specific quantitative evaluation should also combine with the research and analysis about temporal and spatial variations of vegetation coverage, these research can evaluate and guide the desertification management. However, there are few researches on the temporal and spatial variation of vegetation coverage of desert using vegetation index. Therefore, this paper takes Maowusu sandy land as the research area, using MODIS NDVI data from 2006 to 2016, introducing meteorological data, studying the temporal and spatial variations of vegetation coverage, and analyzing the response characteristics of vegetation coverage to temperature and precipitation in the study area. The purpose is to establish a complete model of spatial and temporal change analysis and evaluation of vegetation cover in sandy land, which can be used in the related research work in the future, which is of guiding significance to the planning and evaluation of desertification management.

\section{STUDY AREA AND DATA}

\subsection{Introduction to Study Area}


Maowusu sand land is located at the junction of Shaanxi, Inner Mongolia and Ningxia provinces, and is seated on the concave surface of alluvial plain between Loess Plateau and Erdos Plateau. Its range is $37^{\circ} 27^{\prime} 30^{\prime \prime}-29^{\circ} 22^{\prime} 30^{\prime \prime} \mathrm{N}$ and $107^{\circ} 20^{\prime} 00 " 111^{\circ}$ $30^{\prime} 00^{\prime \prime}$ E with a total area of about 40,000 km2 (see Fig. 1).

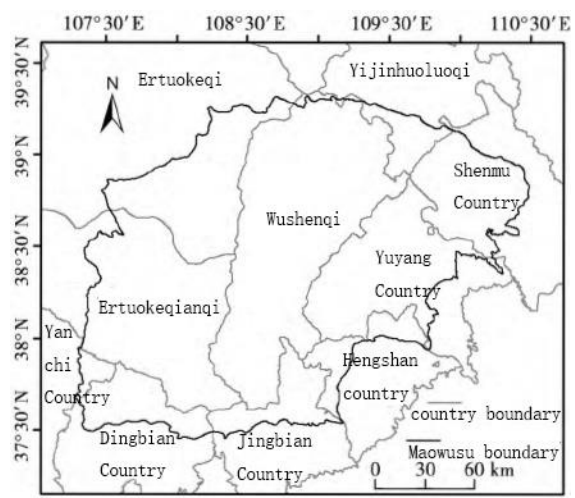

Fig.1 The boundary of Maowusu sandy land

Maowusu sandy land is one of the four major sandy areas in China, and has typical features in the geography, climate, environment, governance and other aspects (Ren, 2002). It is in a climate transitional zone, from southeast to northwest, followed by arid, semi-arid and humid zone. In this area, the precipitation decreased from southeast to northwest, and most concentrated in July to September, the annual average temperature is $6.0 \sim 8.5^{\circ} \mathrm{C}$. The vegetation types show a larger difference in the region, the northwest edge of the desert is desert steppe, the eastern and central belong to typical grassland, and the southeast presents a transition to forest grassland.

\subsection{Data and Processing}

This paper selects 2006-2016 MODIS NDVI data with a spatial resolution of $500 \mathrm{~m}$ and temporal resolution of $16 \mathrm{~d}$. There are totally 253 phases in 11 years, and one phase contains two images.

Meteorological data is from China Meteorological Data Service Network. In this study, 33 meteorological stations around the study area are selected. The temperature and precipitation elements from the dataset of Monthly Dataset of China's Terrestrial Climatological Data are used.

Data processing flow chart shown in Fig. 2. In the pre-processing, the vector boundary of Maowusu sandy land is obtained after registration and vectorization, and its projection mode and coordinate standard are set as UTM 49zone WGS-84. Then the images are mosaicked, re-projection, cropped and time-series reconstruction. And the raster data of temperature and precipitation are obtained by interpolation. On the basis of preprocessing, the NDVI, temperature and precipitation of the study area are calculated by averaging all pixels. The spatio-temporal distribution and variation of NDVI and the response of NDVI to temperature and precipitation were analyzed.

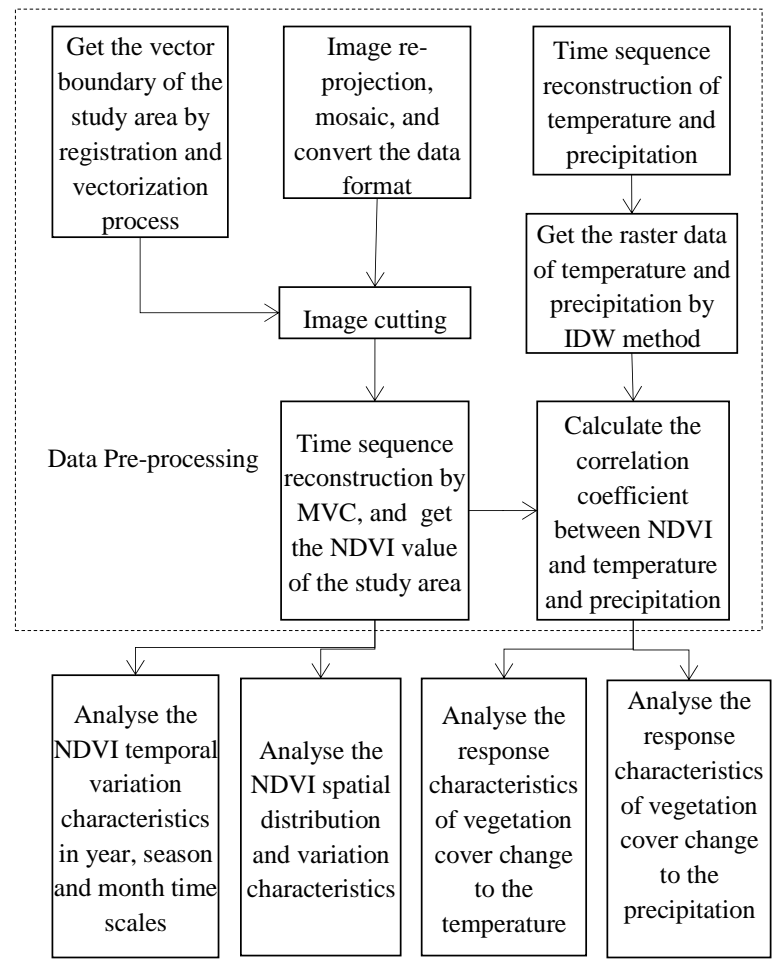

Fig.2 The flow chart of data processing

\section{RESEARCH METHODS}

In this study, MVC (Maximum Value Composite) is used for time series reconstruction of NDVI data, the temperature and precipitation data are interpolated by using IDW (inverse distance weighting), and the temporal variation of vegetation cover is studied by using unary linear Regression analysis. Finally, analyse the response characteristics of vegetation cover change to temperature and precipitation by using Pearson correlation coefficient.

\subsection{Maximum Value Composite}

MVC is the most popular method of NDVI time series reconstruction (Holben, 1986; Fensholt et al., 2012). The method assumes that in a data sequence, there is always one cloud-free value in each pixel, which has a highest value. So we can calculate to obtain the maximum value of each pixel as the pixel value of the resulting image.the formula is expressed as:

$$
X_{\text {new }}=\operatorname{MAX}\left(X_{1}, \cdots, X_{k}\right)
$$

Where $X_{k}=$ the pixel value of the $\mathrm{i}$-th scene image

\subsection{Inverse Distance Weighting}

It is generally assumed that anything distributed in geospatial space does not exist in isolation and has some spatial correlation with the surrounding things. Spatial interpolation is a method that using the known points to predict the unknown around, the common interpolation methods include IDW (inverse distance weighting), Kriging and spline functions. In this study, we interpolate the temperature and precipitation grid map of the study area based on the meteorological data of 33 site by using the method of IDW. the formula is expressed as:

$$
Z=\sum_{i=1}^{n} \frac{1}{d_{i}^{p}} z\left(x_{i}\right) / \sum_{i=1}^{n} \frac{1}{d_{i}^{p}}
$$


Where $Z(x i)=$ the data of the $\mathrm{i}$-th weather station $n=$ the amount of weather stations used for interpolation $d_{i}=$ is the distance from the interpolation point to the ith weather station

\subsection{Unary Linear Regression Analysis}

Unary linear regression analysis model can describe the trend of NDVI time series. Douglas et al. (2004) used this model to calculate and analyse the GRC (Greenness Rate of Change), GRC is the slope of the univariate linear regression equation of NDVI time series changes. The formula is expressed as:

$$
\text { slope }=\sum_{i=1}^{n}\left(X_{i}-\bar{X}\right)\left(Y_{i}-\bar{Y}\right)
$$

Where $X_{i} Y_{i}=$ the $\mathrm{i}$-th value of variable $\mathrm{x}, \mathrm{y}$ respectively $\bar{X} \bar{Y}=$ the average of variable $\mathrm{x}, \mathrm{y}$ respectively

GRC can represent the trend of the vegetation index of a pixel or a research area in a time series, if the value is positive, indicating that the vegetation coverage becomes larger. According to the value, the trend of NDVI can be divided into seven levels (Han et al., 2016), see Table 1.

\begin{tabular}{cc}
\hline Slope & Change level \\
\hline$<-0.0090$ & Seriously degraded \\
$-0.0090 \sim-0.0046$ & Moderate degraded \\
$-0.0045 \sim-0.0010$ & Slight degraded \\
$-0.0009 \sim 0.0009$ & Unchanged \\
$0.0010 \sim 0.0045$ & Slightly improved \\
$0.0046 \sim 0.0090$ & Moderate improved \\
$>0.0090$ & Obviously improved \\
\hline
\end{tabular}

Tab.1 The grades of NDVI change trend

\subsection{Pearson Correlation Coefficient}

Correlation analysis is to study whether there is a special relationship between the two phenomena, and to analyse this dependency relationship to obtain its relevant direction and degree of correlation. The correlation coefficient is a measure of the linear correlation between two variables. In this study, we use it to analyse the relationship between vegetation coverage and meteorological factors. The formula is:

$$
R_{X Y}=\frac{\sum\left(X_{i}-\bar{X}\right)\left(Y_{i}-\bar{Y}\right)}{\sqrt{\left(X_{i}-\bar{X}\right)^{2}\left(Y_{i}-\bar{Y}\right)^{2}}}
$$

Where $X_{i} Y_{i}=$ the $\mathrm{i}$-th value of variable $\mathrm{x}, \mathrm{y}$ respectively $\bar{X} \bar{Y}=$ the average of variable $\mathrm{x}, \mathrm{y}$ respectively

\section{RESULTS AND ANALYSIS}

\subsection{NDVI Spatial Distribution and Variation Characteristic}

The NDVI index has a positive correlation with vegetation coverage, so these analysis about NDVI can reflect vegetation coverage changes directly. According to the NDVI index, the vegetation coverage is divided into 6 levels of bare land, sparse vegetation, less vegetation, moderate vegetation, dense vegetation and very dense vegetation (Guo et al., 2002), see table 2.

\begin{tabular}{cc}
\hline NDVI & $\begin{array}{c}\text { Vegetation } \\
\text { coverage levels }\end{array}$ \\
\hline $\mathrm{NDVI} \leq 0.10$ & bare land \\
$0.10<\mathrm{NDVI} \leq 0.15$ & sparse vegetation \\
$0.15<\mathrm{NDVI} \leq 0.30$ & less vegetation \\
$0.30<\mathrm{NDVI} \leq 0.45$ & moderate vegetation \\
$0.45<\mathrm{NDVI} \leq 0.60$ & dense vegetation \\
$\mathrm{NDVI}>0.60$ & very dense \\
\hline
\end{tabular}

Tab. 2 The grades of vegetation coverage

After reclassifying the image in 2016, we get the thematic map of vegetation spatial distribution in Maowusu sandy land, see Fig. 3 . The whole sandy area are less vegetation and moderate vegetation grade, and shows a decreasing trend from southeast to northwest, Dingbian County, Jingbian County in the southern part of the sandy land and Shenmu Country in the eastern part, the vegetation coverage is relatively high, reaching a very dense vegetation level. The vegetation coverage of Ertuokeqi in the northern part of the sandy land is very low, there is a large area of sparse vegetation and bare areas, resulting in a worsen ecoenvironment. The average value of the reclassified images was 0.3890 , among which, the moderate vegetation level accounted for $44.45 \%$ of the whole area, the less and dense vegetation level rankings were $25.03 \%$ and $22.16 \%$ respectively. The bare land accounted for less than $1 \%$.

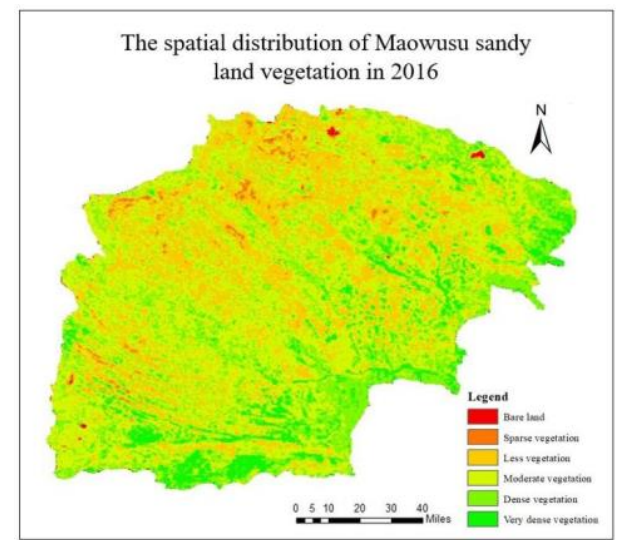

Fig.3 The spatial distribution of Maowusu sandy land vegetation in 2016

Subtracting the two images gets the vegetation cover change over two periods. According to the difference of NDVI, the vegetation cover change is divided into five grades, which are seriously degraded, slightly degraded, unchanged, slightly improved, and significantly improved (Table 3).

\begin{tabular}{cc}
\hline NDVI difference & Change level \\
\hline $\mathrm{DIF}_{\mathrm{NDVI}} \leq-0.1$ & seriously degraded \\
$-0.1<\mathrm{DIF}_{\mathrm{NDVI}} \leq 0$ & slightly degraded \\
$0<\mathrm{DIF}_{\mathrm{NDVI}} \leq 0.1$ & unchanged \\
$0.1<\mathrm{DIF}_{\mathrm{NDVI}} \leq 0.2$ & slightly improved \\
$\mathrm{DIF}_{\mathrm{NDVI}}>0.2$ & significantly improved \\
\hline Tab.3 The grades of vegetation coverage change
\end{tabular}

Subtracting NDVI images every two years from 2006 to 2016, we get the annual change of vegetation cover (Fig. 4). In 20062007, 2011-2012 and 2015-2016, the vegetation coverage have a obvious increase trend, and the most obvious were Ertuokeqianqi, Dingbian County and Hengshan County. During 2013-2014, it shows a significant downward trend, mainly in Etuokeqianqi. 


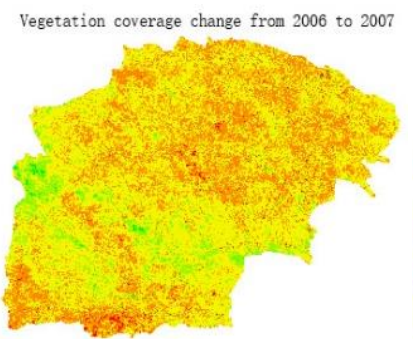

Vegetation coverage change from 2010 to 2011
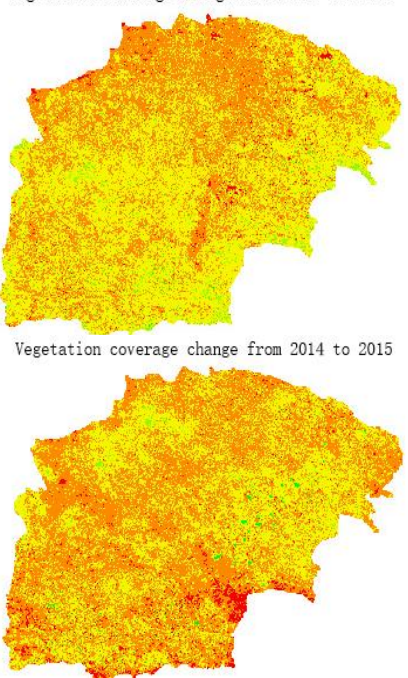

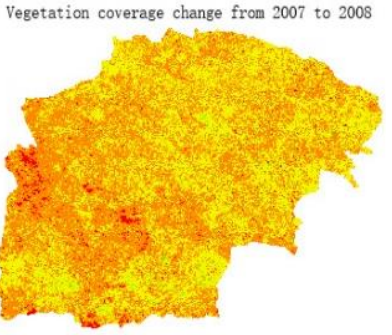

Vegetation coverage change from 2011 to 2012

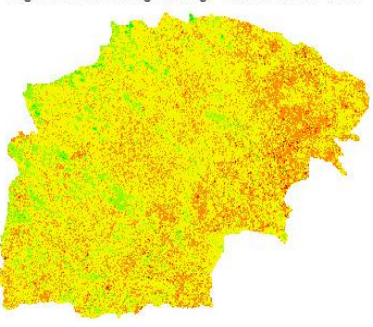

Vegetation coverage change from 2015 to 2016

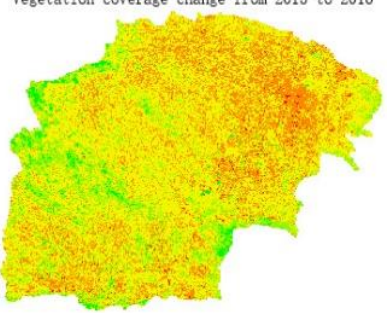

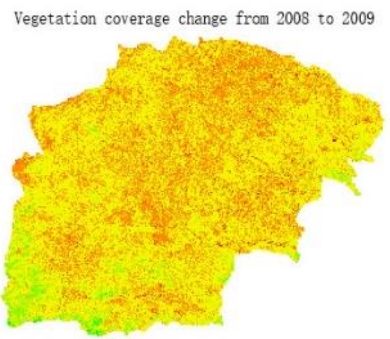

Vegetation coverage change from 2012 to 2013

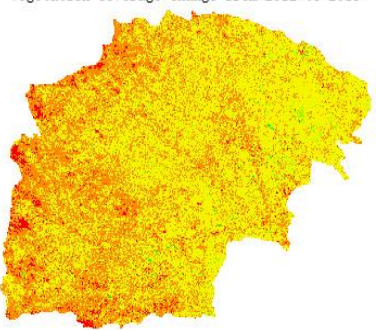

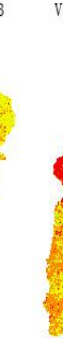

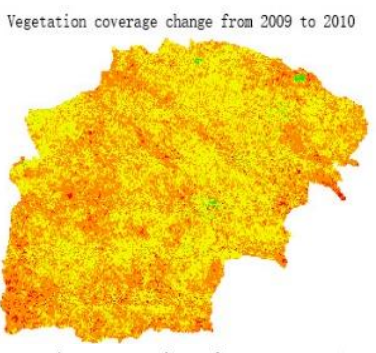

Vegetation coverage change from 2013 to 2014

Legend

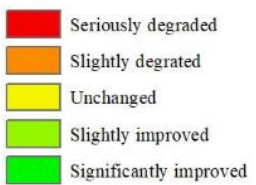

Fig.4 The annual vegetation coverage change from 2006 to 2016

It can be seen that the Etuokeqianqi vegetation coverage is relatively volatile and the ecological environment is relatively fragile. Therefore, we should pay more attention to this area in the future prevention and control of sandy land.

Subtract the images from 2006 and 2016 to obtain the overall change over the 11 years of the study area, as shown in Fig. 5. Most of the sand showed a slight improvement trend, among them, Hengshan County, Shenmu County and Etuokeqianqi showed prominent improvement, while the northern part of Wushenqi, the southern part of Yijinhuoluoqi and the western part of Shenmu County remain unchanged, even parts of the region is deterioration. The image is statistically analyzed, the unchanged area accounted for a maximum of $54.01 \%$, the following is slightly improved level, which accounts for $29.96 \%$. In addition, $6.06 \%$ of the area shows degradation.

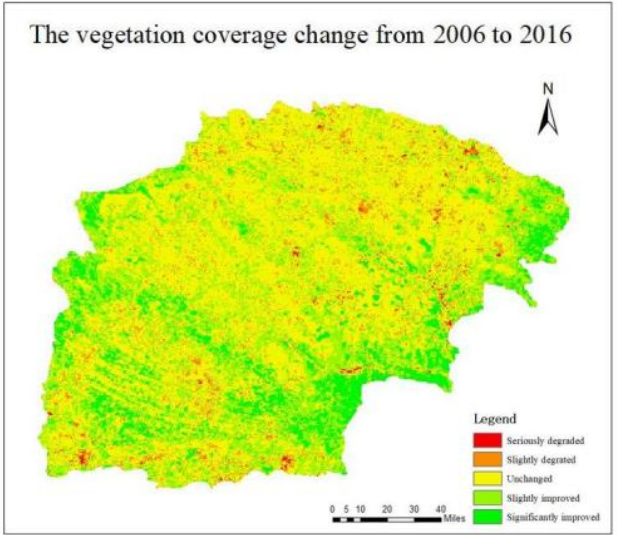

Fig.5 The vegetation coverage change from 2006 to 2016
We can calculate the mean of the NDVIS image that obtained by MVC, then unary linear regression analysis is performed on it (Fig. 6). In the figure, the NDVI value has a steady increasing trend from 2006 to 2016, unary linear regression equation is $\mathrm{y}=$ $0.0075 x+0.2987 R^{2}=0.7115$, the NDVI value shows a steady growth trend at the rate of 0.0075 / a. Referring to Table 1, we can see that it is a moderate improvement. The minimum NDVI in 11 years is 0.2945 in 2006 and the maximum NDVI is 0.3897 in 2016, and the NDVI growth rate is faster in 2007, 2009, 2012 and 2016 .

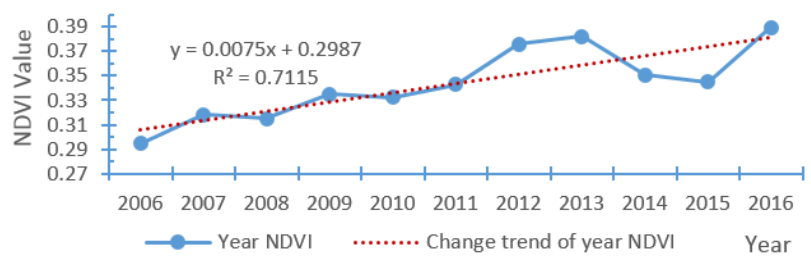

Fig.6 The change trend of annual NDVI

Divide the four seasons according to the rules that March to May is spring, June to August is summer, September to November is autumn, December to January of the next year is winter, then unary linear regression analysis is performed on seasonal data (Fig.7). The vegetation growth in Maowusu sandy land was obviously influenced by the season, and the NDVI values of summer> autumn > spring> winter are respectively 0.3423 , $0.2726,0.2070$ and 0.1437 . The NDVI values of four seasons all performance an increasing tendency, and the growth rate was highest in summer, followed by autumn and spring. In fact, because the Maowusu desert often has snow in winter, which has a great influence on the NDVI value, the NDVI value in winter can't describe the actual situation of vegetation coverage well.

\subsection{NDVI Time Series Variation Characteristics}




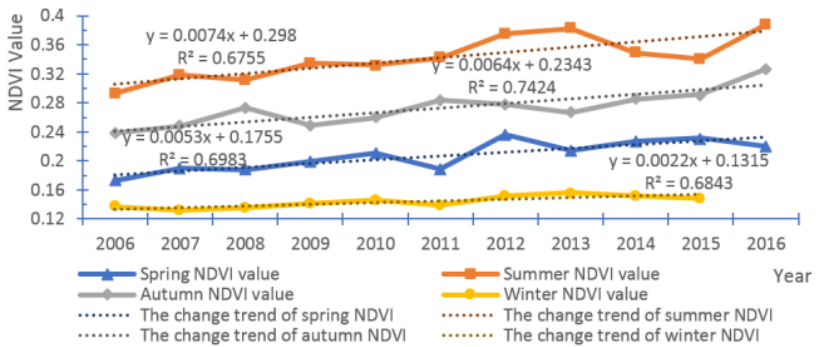

Fig.7 The change trend of seasonal NDVI

The monthly NDVI data in 11 years are averaged (Fig. 8), the vegetation growth has an obvious annual cycle changing characteristic. The NDVI value change trend fits the gauss distribution of $\mathrm{y}=\frac{1}{\sqrt{2 \pi} * 1.845} e^{-\frac{(x-7.493)^{2}}{2 * 1.845^{2}}}$ within year, and the largest value is 0.3282 in August. A threshold method is used to determine the plant growth cycle, where the indication within the threshold is the plant growth period, and the indication outside the threshold is the plant dormancy period. The minimum threshold for identifying plants is set as 0.14 . It can be seen from the figure that the vegetation green up stage is in the beginning of April, and withering stage is in the middle of November, the growth period is about $220 \mathrm{~d}$.

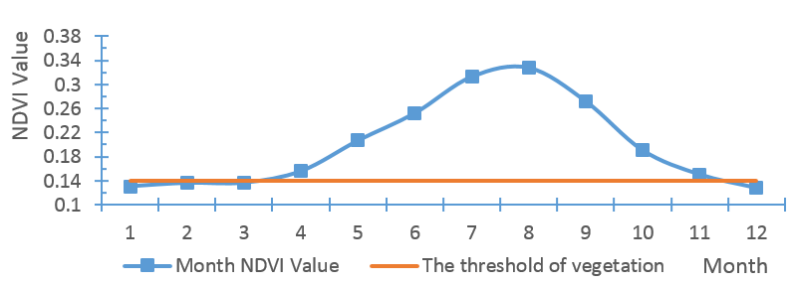

Fig. 8 The change trend of mensal NDVI

\subsection{The Response of NDVI to Temperature}

According to the selected data of 33 stations, this study interpolates the raster image data of temperature and precipitation in the study area by IDW.

The spatial distribution of temperature in 2015 can be seen in Fig.9, from south to north, the temperature is declining. Hengshan County and Jingbian County have the highest temperatures, with a value of $10.89^{\circ} \mathrm{C}$. Etuoke and Yijinhuoluo have the lowest temperatures, with a value of $7.983^{\circ} \mathrm{C}$.

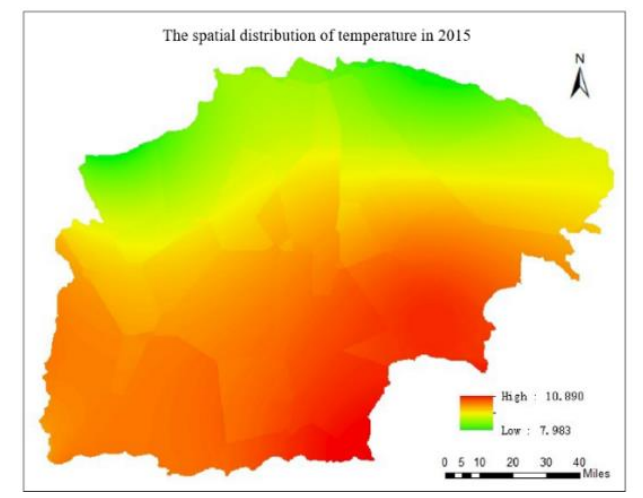

Fig.9 The spatial distribution of temperature in 2015

From the change trend of annual temperature (Fig.10), we can see that during the inter-annual temperature, the volatility is relatively large and there is no obvious steady growth or decline. Analyse the correlation of annual NDVI and annual temperature, its correlation coefficient is -0.2178 , that is, the temperature has a weak negative correlation with NDVI. The reason is that the ecological environment in Maowusu sand land is rather poor and the growth of vegetation is poor. As the temperature rising, the surface evaporation will be large, and plants can't grow normally due to the lack of water, leading to the NDVI value reduce.

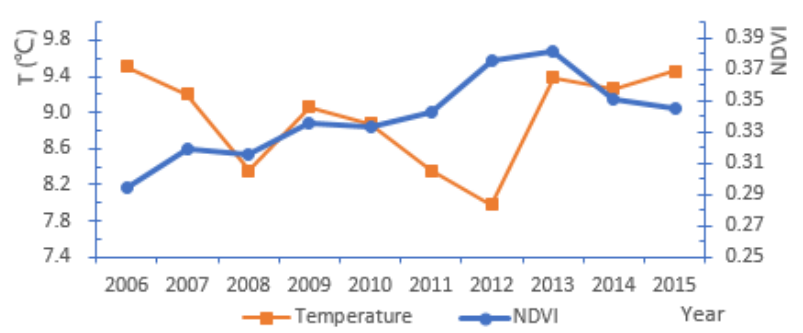

Fig.10 The change trend of annual NDVI and annual temperature

Analyse the correlation of seasonal NDVI and seasonal temperature (Fig. 11), the correlation coefficient of four seasons are $0.1268,-0.3388,-0.0335,0.3184$. The correlation is most obvious in summer, the correlation coefficient between summer and autumn is negative, with the increase of temperature, vegetation grows poorly.
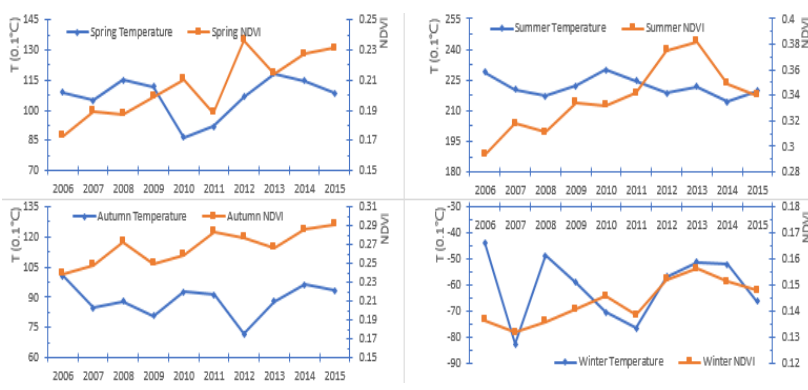

Fig.11 The change trend of seasonal NDVI and seasonal temperature

\subsection{The Response of NDVI to Precipitation}

The spatial distribution of precipitation in 2015 can be seen in Fig.12, among them, the precipitation in Yuyang is the largest with a value of $38.196 \mathrm{~mm} / \mathrm{d}$, and the precipitation in Etuoke is the smallest, with a value of $19.567 \mathrm{~mm} / \mathrm{d}$. The distribution of precipitation has a strong similarity with NDVI (Fig.5), this means the positive correlation between them.

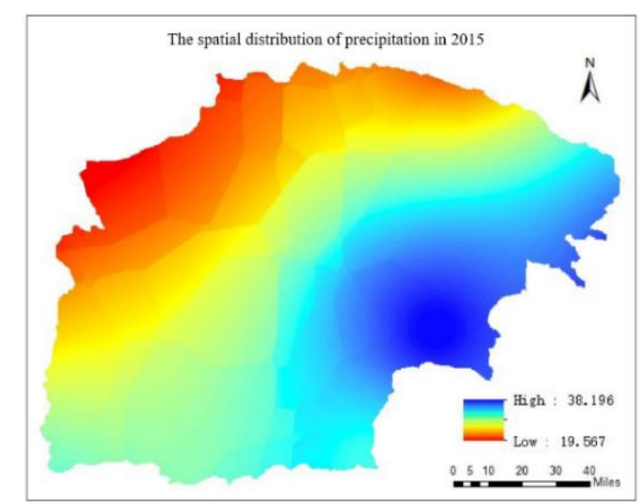

Fig.12 The spatial distribution of precipitation in 2015

From the change trend of annual precipitation (Fig.13), we can see that it has a weaker growth trend, and there is a dramatic increase in 2013. Analyse the correlation of annual NDVI and annual precipitation (Fig.13), its correlation coefficient is 0.6309 , 
NDVI is positively correlated with precipitation, and its correlation is higher than temperature. That is, vegetation growth is mainly affected by precipitation.

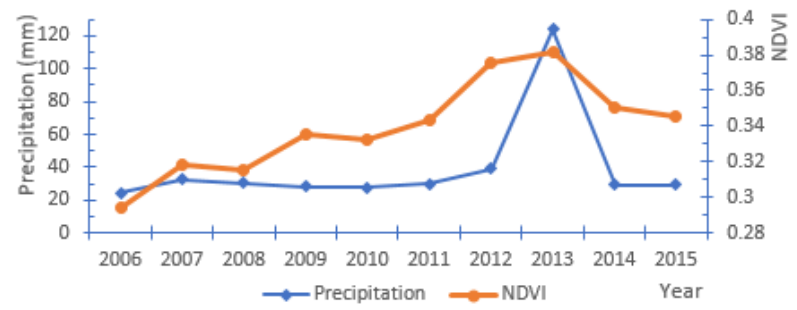

Fig.13The change trend of annual NDVI and precipitation

Analyse the correlation of seasonal NDVI and seasonal precipitation (Fig.14), the correlation coefficient of four seasons are $0.2272 、 0.6090 、 0.6874 、 0.6354$. The NDVI of the four seasons is positively correlated with the precipitation data, except for the lower correlation coefficient in spring, the correlations of the other seasons are all significant, and the highest correlation coefficient is 0.6874 in autumn.
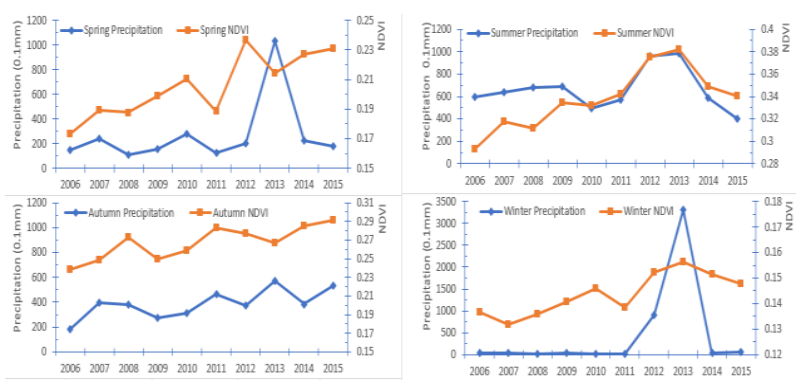

Fig.14 The change trend of seasonal NDVI and precipitation

\section{CONCLUSION AND DISCUSSION}

In this paper, we analyse the spatial and temporal variations of vegetation coverage in Maowusu sandy land based on the NDVI values from the perspective of spatial distribution, spatial variation and annual, seasonal, mensal temporal changes. Also analyse the response characteristics of vegetation cover change to temperature and precipitation that may affect the vegetation growth. According to the research and analysis, we can conclude that the ecological environment of Maowusu sandy land has a obvious and continuous improvement trend in recent 11 years, and it is more closely related to the increase of precipitation. A complete set of vegetation cover analysis and evaluation model for sandy land is established, and it will be very important for the sand ecological environment protection in the future.

In this study, we take the average value of the whole image for correlation analysis, and follow-up study can adopt the method of pixel-by-pixel analysis. In addition, the lagging effects of climatic factors need to be considered.

\section{ACKNOWLEDGEMENTS (OPTIONAL)}

This work was supported by the National Natural Science Foundation of China (Grant No. 41771449).

\section{REFERENCES}

Douglas, A., Allen, H., David, V., Fred, H., at al, 2004. Remote sensing of vegetation and land - cover change in Arctic Tundra Ecosystems. Remote sensing of environment, 89 (3), pp. 281 308 .
Du, J., Zhao, C., et al, 2015. Dynamic changes in vegetation NDVI from 1982 to 2012 and its responses to climate change and human activities in Xinjiang, China. Chinese Journal of Applied Ecology, 26(12), pp. 3567-3578.

Fensholt, R., Proud, S., 2012. Evaluation of earth observation based global long-term vegetation trends-comparing GIMMS and MODIS global NDVI time-series. Remote Sensing of Environment, 119, pp. 131-147.

Guo, N., Li M., Ma S., 2002. Oasis vegetation change in Gansu Hexi area by the metrological satellite monitoring. Journal of Arid Meteorology, 20(1), pp. 033-035.

Han R., Liu P., Ma C., et al, 2016. NDVI 3g trend and its response to climate change in Ordos during period from 1982 to 2012. Bulletin od Soil and Water Conservation, 36(5), pp. 028-033.

Holben, B., 1986. Characteristics of maximum-value composite image from temporal AVHRR data. International Journal of Remote Sensing, 7(11), pp. 1417-1434.

Jiapaer, G., Chen, X., Bao, A., 2011. A comparison of methods for estimating fractional vegetation cover in arid regions. Agricultural and Forest Meteorology, 151, pp. 1698-1710.

Lamchin, M., Lee, J., Lee W., et al, 2016. Assessment of land cover change and desertification using remote sensing technology in a local region of Mongolia. Advances in Space Research, 5, pp. 64-77.

Lin, Y., Li C., Liu, Z., et al, 2016. Assessment of spatial-temporal variations in vegetation cover in Xinjiang from 1982 to 2013 based on GIMMS-NDVI. Acta Ecologica inica, 36(19), pp. 6198-6208.

Li, S., Yan, J., Wan, J., et al, 2012. The Spatial-temporal Changes of Vegetation Restoration on Loess Plateau in Shaanxi-GansuNingxia Region. Acta Geographica Sinica, 67(7), pp. 960-970.

$\mathrm{Mu}$, S., Li, J., Chen, Y., et al, 2012. Spatial Differences of Variations of Vegetation Coverage in Inner Mongolia during 2001-2010. Acta Geographica Sinica, 67(9), pp. 1225-1268.

Ren, C., 2002. Study on the causes of desertification in Maowusu area. Journal of Geological Hazards and Environment Preservation, 6(2), pp. 30-31.

Setiawan, Y., Yoshino, K., Prasetyo, L., 2014. The dynamics change of vegetation cover on tropical forestlands using multitemporal MODIS EVI. International Journal of Applied Earth Observation and Geoinformation, 26, pp. 132-144.

Song, F., Xing, K., Liu, Y., et al, 2011. Monitoring and assessment of vegetation variation in Northern Shanxi based on MODIS/NDVI. Acta Ecologica Sinica, 31(2), pp. 0354-0363.

Wang, Y., Zhang, J., Ma, Q., Zhu, M., 2016. Response of aeolian desertification to regional climate change in Horqin sandy land at beginning of 21 st century. Transactions of the Chinese Society of Agricultural Engineering, 32(Supp.2), pp. 177-185.

Wang, Y., Zhang J., Tong, S., et al, 2017. Monitoring the trends of aeolian desertified lands based on time-series remote sensing data in the Horqin Sandy Land, China Catena, 157, pp. 286-298. 
The International Archives of the Photogrammetry, Remote Sensing and Spatial Information Sciences, Volume XLII-3, 2018 ISPRS TC III Mid-term Symposium "Developments, Technologies and Applications in Remote Sensing", 7-10 May, Beijing, China

Xiao, Q., Tao, J., Xiao, Y., et al, 2017. Monitoring vegetation cover in Chongqing between 2001 and 2010 using remote sensing data. Environ Monit Assess, 189, pp. 493.

Zhao, Y., Ding, G., Wang, X., et al, 2003. Main models to combat desertification in China. Research of soil and water conservation, 9(3), pp. 118

Zhu, F., Lu, H., Yi S., et al, 2017. Temporal and Spatial Variation Law of Hunshandake Sandy Land Vegetation Based on NDVI Index. Soil and Water Conservation in China, 3, pp. 31-33. 